\title{
Results of Double-blind, Multicentre Study with Ritodrine in Premature Labour
}

\author{
A. WESSELIUS-DE CASPARIS, \\ O. GAMISANS, J. G. STOLK, W. VIVIER \\ A. YO LE SIAN, K. BAUMGARTEN, I. BROSENS,
}

\section{Patients and Methods}

\section{Summary}

A double-blind placebo-controlled multicentre study with ritodrine, a $\beta$-mimetic uterine relaxant, has been performed in 91 patients in premature labour. All patients were treated according to a fixed dosage scheme consisting of an intravenous infusion followed by oral tablets for a total of seven days. Ritodrine arrested premature labour in $80 \%$, the placebo in $48 \%$ of the patients $(P=0.02)$. This short treatment, however, was usually not sufficient to prolong gestation till term. Apart from a slight to moderate rise in maternal heart rate and a slight rise in systolic blood pressure, ritodrine did not give rise to any maternal or fetal side effects. The problems of patient selection and of evaluation of the results are discussed.

\section{Introduction}

Potent drugs exist which effectively suppress uterine contractions during spontaneous or oxytocin-induced labour. These uterine relaxants like isoxsuprine (Hendricks et al., 1961; Allen et al., 1965), ritodrine (Baumgarten, 1969; Baumgarten et al., 1969; Coutinho et al., 1969; Gamissans et al., 1969; Hüter et al., 1969; Landesman et al., 1971), orciprenaline (Mouleón Alegre and Brugget Auban, 1950; Baillie et al., 1970) buphenine (Wolff, 1967; Neumann and Manteuffel, 1970) belong mainly to the $\beta$-adrenergic groups of compounds. They are often recommended for the treatment of premature labour with the aim of postponing delivery, but it is often questioned whether they can indeed prolong pregnancy, for the following reasons: (1) the diagnosis of premature labour is ill defined, and (2) the effect of conservative treatment like bed rest, sedation, and psychological support is unknown.

A double-blind investigation of the efficacy of any of the drugs mentioned above has not been published so far. Therefore we have undertaken a multicentre, double-blind, placebocontrolled trial to study the effect of ritodrine (Prempar; DU 21220) (see diagram) in postponing delivery in premature labour. It is a predominantly $\beta$-sympathicomimetic drug, which is pharmacologically active after parenteral and oral administration and which has not been shown to give rise to serious cardiovascular side effects, in particular not to hypotension.

Philips-Duphar, Clinical Research Department, Weesp, Holland

A. WESSELIUS-DE CASPARIS, M.D.

University Hospital, Ghent, Belgium

M. THIERY, M.D.

A. YO LE SIAN, M.D.

II Women's University Hospital, Vienna, Austria

K. BAUMGARTEN, M.D.

University Hospital, Louvain, Belgium

I. BROSENS, M.D.

Santa Cruz and San Pablo Hospital, Barcelona, Spain

O. GAMISSANS, M.D.

Diaconessen Hospital, Arnhem, Holland

J. G. STOLK, M.D.

St. Pierre University Hospital, Brussels, Belgium

W. VIVIER, M.D.
The criteria for inclusion in the trial were that the patient must present between the 20th and 36th weeks of pregnancy, according to the duration of amenorrhoea, with a diagnosis of premature labour based on the presence of one or more of the following signs or symptoms: loss of blood-stained mucus plug ("show"), palpable uterine contractions, and cervical dilatation. No patients were excluded because of ruptured membranes, toxaemia of pregnancy, or other maternal or fetal complications, unless prolongation of the pregnancy was considered to endanger the fetus.

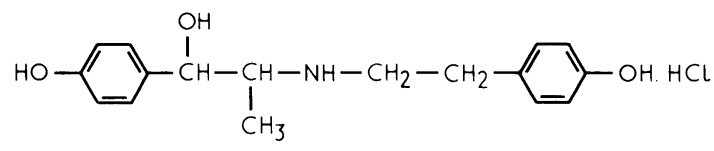

Structural formula of ritodrine, presented as its salt from hydrochloric acid.

Current treatment of premature labour consists in bed rest and sedation, since no effective specific treatment exists. Ritodrine has been studied extensively for its relaxant effects on spontaneous or oxytocin-induced uterine contractions, and the results justified a clinical trial to see if it did indeed postpone delivery. Thus all the patients in the trial got the standard treatment of the hospital and, in addition, received either ritodrine or a placebo. Thus the patients in the placebo group were given all benefits of treatments currently available and no drug known to be effective was withheld.

All the patients were informed that they were taking part in an investigation of a new drug which could give rise to certain side effects like tachycardia and palpitation and that they were free to refuse to enter the trial.

The patients were allocated at random to treatment with ritodrine or a placebo of identical appearance in a double-blind manner. The code key was not available to the investigators. The treatment consisted of an intravenous infusion for 24 to 48 hours followed by a course of oral administration for five to seven days. The total duration of treatment did not exceed eight days. The parenteral dose was $200 \mu \mathrm{g} / \mathrm{min}$, to be decreased if side effects occurred; the oral dose was $10 \mathrm{mg}$ four times daily. Bed rest was prescribed for the first four days and gradual mobilization thereafter. As the patients were in hospital it could be confirmed that they actually ingested the oral dose. If in any patient the symptoms of premature labour recurred after completion of the first course of treatment, she was considered as a new case in the study. Blood pressure, maternal heart rate, and fetal heart rate were checked at least at hourly intervals during intravenous administration and at least three times daily during oral treatment.

\section{Results}

A total of 91 patients with 109 treatments were originally included in the trial. Ultimately 81 patient forms from 63 
patients could be evaluated. The others were discarded because of incomplete data, not following the treatment scheme, no follow-up till delivery, or caesarean section because of placenta praevia. The composition of the ritodrine and the placebo groups is shown in Table I. The two groups are statistically comparable (Table II). The results from the patients with ruptured membranes and those with intact membranes were statistically evaluated separately.

The clinical effectiveness of the drug was evaluated in three ways; (1) arrest of premature labour to beyond the treatment period, (2) assessment of the duration of the length of gestation at time of delivery, and (3) the interval in days between the start of treatment and the onset of labour, either premature or at term.

Arrest of Premature Labour.-Premature labour was arrested and delivery postponed to beyond the treatment period in $80 \%$ of the patients receiving ritodrine, while in the group receiving the placebo this was seen in $48 \%$ of the cases (Table III). The difference between the two groups is significant $(\mathbf{P}=0.02)$.

Duration of Gestation at Delivery.-A further differentiation of the results of treatment is given in Table IV, which shows the duration of gestation at delivery. Since some patients were treated twice the number of infants born is smaller than the number of treatments shown in Table II. The incidence of double treatments was the same in each group. The number of full-term deliveries was about equal in the two groups.

Gain in Days.- The gain in days is defined as the number of days between the first day of treatment and either delivery or further contractions (new treatment). The comparison between the two treatments in terms of numbers of days is shown in Table V. The difference between the ritodrine and placebo groups was statistically significant.

\section{FAILURES OF RITODRINE TREATMENT}

Treatment with ritodrine failed in 17 of the 43 patients (Table VI)-in 11 complicating factors existed suggesting why treatment may not have been effective and in six no known reason for the failure was found.

\section{SIDE EFFECTS}

Cardiovascular Effects.-Blood pressure and maternal heart rate were fluctuating during the treatment period. As measure-

TABLE I-Composition of the Ritodrine and the Placebo Groups

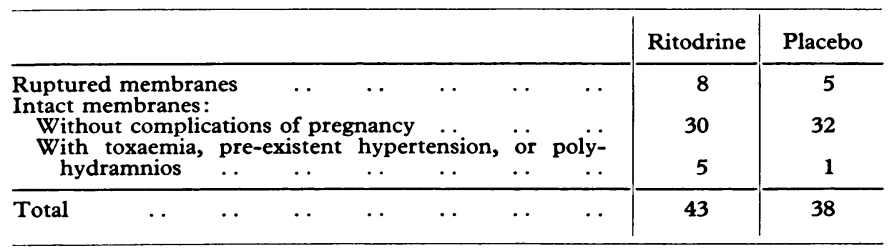

TABLF II-Mean Values and Standard Deviations showing Comparability of the Ritodrine and Placebo Groups

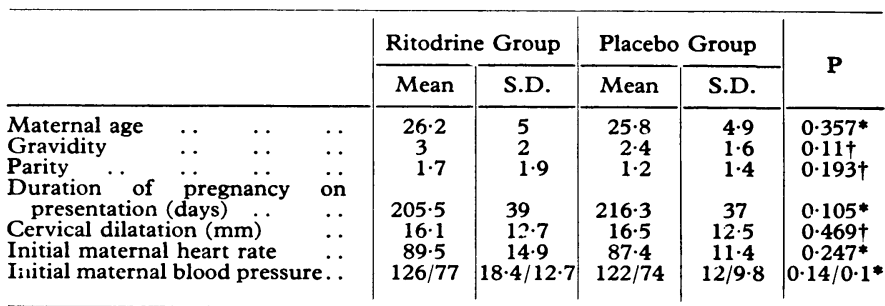

S.D. = Standard deviation of the individual data. $\mathbf{P}=$ Significance of the differences

* Student's $:$ test (Mainland, 1963a).

† W'ilcoxon's test (one sided) (Mainland, 1963b)

TABLE III-Arrest of Premature Labour

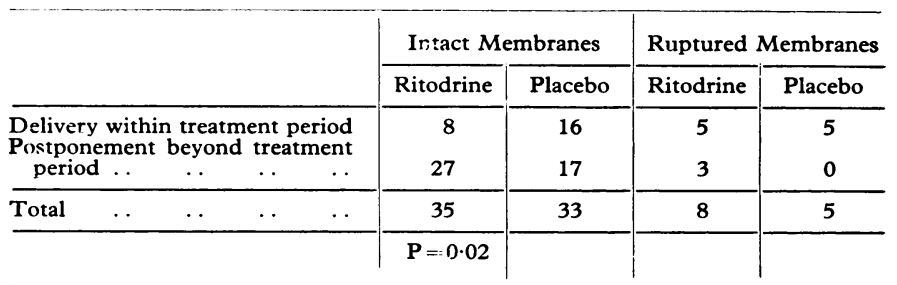

$\mathbf{P}=$ Difference in distribution of frequency in ritodrine and placebo group (Mainland, $P=$ Differ
$1963 c)$.

TABLE IV-Duration of gestation at Delivery

\begin{tabular}{|c|c|c|c|c|c|c|c|}
\hline & & & & \multicolumn{2}{|c|}{ Intact Membranes } & \multicolumn{2}{|c|}{ Ruptured Membranes } \\
\hline & & & & Ritodrine & Placebo & Ritodrine & Placebo \\
\hline \multicolumn{4}{|c|}{$\begin{array}{l}\text { Delivery within treatment period } \\
\text { Delivery beyond treatment period } \\
\text { but still premature }<38 \text { weeks } \\
\text { Delivery beyond treatment period } \\
\text { but at term } \quad . \\
\end{array}$} & $\begin{array}{r}8 \\
12 \\
6 \\
\end{array}$ & $\begin{array}{r}16 \\
1 \\
8\end{array}$ & $\begin{array}{l}5 \\
1 \\
1\end{array}$ & $\begin{array}{l}5 \\
0 \\
0\end{array}$ \\
\hline \multirow[t]{2}{*}{ Total } & . & .. & . & 26 & 25 & 7 & 5 \\
\hline & & & & $P=0.00$ & & & \\
\hline
\end{tabular}

$\mathbf{P}=$ Difference in distribution of frequency in ritodrine and placebo group.

TABLE v-Interval between Start of Treatment and Onset of Labour

\begin{tabular}{ll|c|c|c|c}
\hline & \multicolumn{2}{|c|}{ Intact Membranes } & Ruptured & Membranes \\
\cline { 2 - 5 } & Ritodrine & Placebo & Ritodrine & Placebo \\
\hline Mean gain in days per case &.. & 28.2 & 17.4 & 8.4 & 1.2 \\
\hline & & $P=0.01$ & $P=0.057$
\end{tabular}

$P$ values tested according to Wilcoxon's two-sample test.

\section{TABLE VI-Failures in Ritodrine Group}

Toxaemia + accidental haemorrhage; infusion stopped because of intrauterine

fetal death
Retroplacental haematoma; contractions not stopped Cervical incompetence + polyhydramnios ...

Ruptured membranes

Hodgkin's disease; contractions not stopped

Dosage reduced because of side effects; contractions recurred

Cervical dilatation $3-4 \mathrm{~cm}$; contractions only temporarily stopped

\begin{tabular}{|c|c|c|c|c|c|c|c|c|c|c|c|c|c|c|}
\hline & & & \multicolumn{4}{|c|}{ Pretreatment Values } & \multicolumn{4}{|c|}{ During Intravenous Infusion } & \multicolumn{4}{|c|}{ During Oral Treatment } \\
\hline & & & \multicolumn{2}{|c|}{ Ritodrine Group } & \multicolumn{2}{|c|}{ Placebo Group } & \multicolumn{2}{|c|}{ Ritodrine Group } & \multicolumn{2}{|c|}{ Placebo Group } & \multicolumn{2}{|c|}{ Ritodrine Group } & \multicolumn{2}{|c|}{ Placebo Group } \\
\hline & & & Mean & S.D. & Mean. & S.D. & Mean & S.D. & Mean & S.D. & Mean & S.D. & Mean & S.D. \\
\hline Mean maximum systolic blood pressure & $\therefore$ & & $125 \cdot 8$ & $18 \cdot 4$ & $122 \cdot 1$ & $12 \cdot 0$ & $133 \cdot 3$ & $14 \cdot 4$ & $130 \cdot 0$ & $12 \cdot 4$ & 125.8 & $12 \cdot 0$ & $109 \cdot 2$ & 27.9 \\
\hline $\begin{array}{l}\text { Mean minimum diastolic blood pressure } \\
\text { Mean maximum maternal heart rate } . .\end{array}$ & $\therefore$ &. & $\begin{array}{l}77.3 \\
89.5\end{array}$ & $\begin{array}{l}12.7 \\
14.9\end{array}$ & $\begin{array}{l}74 \cdot 1 \\
87 \cdot 4\end{array}$ & $\begin{array}{r}9 \cdot 8 \\
11 \cdot 4\end{array}$ & $\begin{array}{r}61 \cdot 1 \\
122 \cdot 4 \\
(\mathrm{P}\end{array}$ & $\begin{array}{l}16 \cdot 7 \\
19 \cdot 5 \\
01)\end{array}$ & $\begin{array}{r}66 \cdot 6 \\
100 \cdot 8\end{array}$ & $\begin{array}{l}15 \cdot 6 \\
21 \cdot 4\end{array}$ & $\begin{array}{r}66.8 \\
107.2 \\
(P=\end{array}$ & $\begin{array}{l}11.7 \\
19 \cdot 3 \\
06)\end{array}$ & $\begin{array}{l}60 \cdot 4 \\
93 \cdot 3\end{array}$ & $\begin{array}{l}14 \cdot 4 \\
29 \cdot 0\end{array}$ \\
\hline Mean maximum fetal heart rate & .. & .. & & & & & 153.4 & $16 \cdot 2$ & $149 \cdot 2$ & 8.7 & $149 \cdot 0$ & $8 \cdot 3$ & $149 \cdot 6$ & $9 \cdot 7$ \\
\hline
\end{tabular}

$P$ values refer to significance of difference of mean values in the two treatment groups. 
ments of the cardiovascular effect of ritodrine we have taken the maximum systolic and the minimum diastolic blood pressure and the maximum increase in maternal heart rate. The effect of intravenous and oral ritodrine is summarized in Table VII. The difference of the maximum maternal heart rate during ritodrine infusion and the pretreatment value was highly significant; the difference during oral treatment was nearly significant. The systolic blood pressure during oral ritodrine treatment shows a significant difference compared with the placebo value, but was equal to the pretreatment value. The fetal heart rate did not change significantly.

Postpartum Haemorrhage.- In both the placebo and the ritodrine group there were four patients with an estimated postpartum blood loss of more than $500 \mathrm{ml}$.

Apgar Score.-There was no stastically significant difference between the two groups in the one-minute and five-minute Apgar scores (Table VIII).

TABLE VIII-Apgar Score

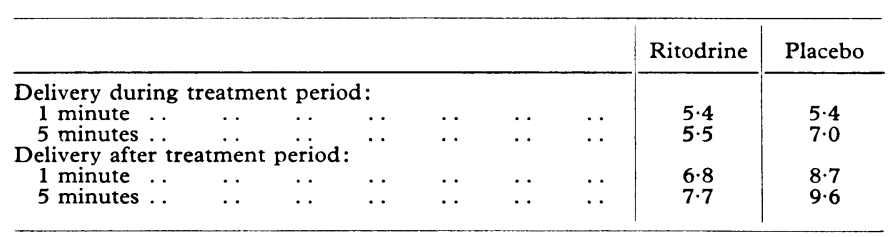

P value between 0.15 and 0.4 (tested according to Wilcoxon's two-sample test).

\section{Discussion}

The first problem in designing this controlled study in premature labour was to define the criteria on which a patient should be included in the trial. Owing to lack of objective signs by which the start of true labour can be diagnosed for certain, we used as criteria for selection the presence of one or more of less specific symptoms, realizing that by doing so perhaps patients in "false" labour would also be included. From the beginning we distinguished between two groups of patients-those with intact membranes and those with ruptured membranes. However, only the first group became large enough for proper statistical evaluation. For the sake of completeness the results in the ruptured membrane group are described, though no valid conclusion can be drawn. The placebo arrested premature labour in $48 \%$ of patients. This could indicate that premature labour was misdiagnosed or that bed rest alone might have been effective. Ritodrine postponed labour to beyond the treatment period in $80 \%$ of the cases. The difference in efficacy between ritodrine and placebo was highly significant $(P=0.005)$. We do not know why ritodrine failed in six patients in whom there were no apparent complicating factors. Perhaps higher dosages than the standard $200 \mu \mathrm{g} / \mathrm{min}$ would have yielded better results.

When analysing the stage of development of the fetus at delivery we came to the conclusion that treatment for one week with ritodrine was usually sufficient to arrest premature labour during the treatment period and for some time beyond it, but not to prolong pregnancy till term. The main difference between the ritodrine and the placebo results lies in the number of deliveries within the treatment period and the number postponed to beyond that time though still premature (Table IV). A longer treatment using an individually tailored dosage scheme might prolong gestation to term in more cases.

One of us (Yo Le Sian, 1970) has already had some experience in this respect. His share in our double-blind study was 26 patients with the fixed dosage scheme: $44 \%$ were born still premature and $23 \%$ at term in the ritodrine group. Nineteen patients selected by the same criteria and of a comparable gestation were later treated by the same investigator with individual dosage schemes. Only $5 \%$ of the babies were born prematurely and $68 \%$ at term. The difference between the two treatment schemes is statistically significant $(P<0.01)$.

All the investigators are now partaking in a new multicentre trial with the same selection criteria but with the dose and total duration of treatment adjusted to the individual response of the patient.

The gain in days is in our opinion a less important criterion, because it does not take into account at what duration of gestation the patient entered the study and thus how many days potentially can be gained. The difference of nine days between the ritodrine and the placebo groups is statistically significant $(\mathrm{P}=0.03)$ but unimpressive. However, we would stress that even a small prolongation of eight to nine days can be of considerable benefit to the baby.

The study confirms the cardiovascular effects, described in detail in the human pharmacological studies on ritodrine. There is a clear increase in maternal heart rate during the ritodrine infusion and a tendency to an increase in pulse pressure. In only one case were the side effects of such a degree that the dosage of the intravenous infusion had to be decreased. Otherwise the drug was well tolerated.

Since $\beta$-mimetic drugs may also be peripheral vasodilators we checked if ritodrine caused an increase in blood loss after delivery. In both groups there were four patients with an estimated postpartum blood loss of more than $500 \mathrm{ml}$. None of the cases occurred in women who delivered within the treatment period with ritodrine. The fetal heart rate did not change significantly during the ritodrine treatment. There was no difference in Apgar score between babies born after ritodrine and placebo treatment and no reported congenital malformation, suggesting that the drug is harmless to the fetus. This fact has been confirmed by two recently reported studies on the use of ritodrine in the treatment of intrapartum fetal acidosis and fetal distress during labour (Gamissans et al., 1970, 1971).

The results of trials of a particular form of treatment of premature labour are very much dependant on the selection criteria and even on the individual clinician. This is illustrated by studies with isoxsuprine which show a "success" rate which may vary from 40 to $70 \%$. This is a clear indication that it is not valid to compare the results of treatments in different centres to evaluate the efficacy of a form of treatment.

To investigate whether the difference in response to ritodrine or placebo could be due to differences in comparability of the groups we have been able to compare our patients according to the criteria of comparison recently proposed for the evaluation of controlled trials in premature labour (Flynn, 1970). No differences were seen in maternal age, race, parity, gravidity, abnormal obstetric history, other disorders of pregnancy, clinical urinary tract infection, uterine bleeding, duration of pregnancy at the time of presentation, degree of cervical dilatation and effacement, nature of presenting symptoms, and signs and identity of the investigator. Analysis of social class could not be performed, but taking into account that allocation to treatment was randomized and double blind we felt justified to conclude that the demonstrated difference could not be due to an accident of patient selection.

From this controlied study it can be concluded that ritodrine is a well-tolerated uterine relaxant that can arrest premature labour in most cases. More information is necessary to establish the treatment scheme and duration of treatment with which the highest percentage of term deliveries can be obtained.

We are grateful to Mr. R. van Strik (Statistical Department of N. V. Philips-Duphar, Weesp, Holland) for the statistical evaluation of the results.

\section{References}

Allen, H. H., Short, H., and Fraleigh, D. M. (1965). Applied Therapeutics, Baillie, P., Meehan, F. P., and Tyack, A. J. (1970). British Medical fournal,
4, 154 . 
Baumgarten, K. (1969). Praxis, 58, 519.

Baumgarten, K., Fröhlich, H., Seidl, A., Lim-Rachmat, F, and Sokol, K. (1969). Wiener klinische Wochenschrift 81, 102.

Coutinho, E. M., Bomfim de Sousa F. M., Wilson, K. H., and Landesman, R. (1969). American fournal of Obstetrics and Gynecology, 104, 1053. Flynn, M. J. (1970). Paper presented at the International Symposium on the Highrisk Fetus, Barcelona, October 29-31 1970.

Gamissans, O., Esteban-Altirriba, J., and Maiques, V. (1969). Fournal of Obstetrics and Gynaecology of the British Commonwealth, 76, 656.

Gamissans, O., et al. (1970). Paper presented at the International Symposium on the High-risk Fetus, Barcelona, October 29-31 1970.

Gamissans, O., Esteban-Altirriba, J., and Calaf, J. (1970). To be published. Hendricks, C. H., Cibils, L. A., Pose, S. V., and Eskes, Th. K. A. B. (1961). American fournal of Obstetrics and Gynecology, 82, 1064

Hüter, J. (1969). Therapeutische Umschau, 26, 427.
Landesman, R., Wilson, K. H., Coutinho, E. M., Klima, I. M., and Marcus, R. S. (1971). To be published.

Mainland, D. (1963a). Elementary Medical Statistics, 2nd edn., chapt. 14, p. 287. Philadelphia, Saunders.

Mainland, D. (1963b). Elementary Medical Statistics, 2nd edn., chapt. 14,

Mainland, D. (1963c). Elementary Medical Statistics, 2nd edn., chapt. 12, p. 234. Philadelphia, Saunders.

Mouleón Alegre, F. J., and Brugger Auban, A. J. (1950). Medizinische Klinik (Spanish edition Clinica Medica), 10, 85.

Neumann, H., and Manteuffel, U. (1970). Zentralblatt für Gynäkologie, 92, 1100 .

Wolff, C. H. (1967). Zeitschrift für Geburtshilfe und Gynäkologie, 167, 68 Yo Le Sian, A. (1970). Tijdschrift voor Geneeskunde, 26, 972.

\title{
Problems in the Early Recognition of Congenital Hip Dislocation
}

\author{
GEOFFREY WALKER
}

British Medical fournal, 1971, 3, 147-148

\section{Summary}

Seven cases of infants whose hips were clinically normal at birth, and in whom hip dislocation was later recognized, are reported. In spite of the widespread practice of routine examination of the hips of newborn babies, infants and young children are still presenting with congenital dislocation of the hip. This is probably owing to there being two aetiological types. Every opportunity to re-examine the hips of children under 2 or even 3 years of age must be taken and a high level of suspicion maintained.

\section{Introduction}

Orthopaedic surgeons in children's hospitals and elsewhere continue to see new cases of congenital hip dislocation and dysplasia in spite of the efforts being made in maternity departments and general practice to detect this crippling disorder by clinical examination within the first few days after birth. It now seems reasonably certain that the hips of a newborn infant may be clinically normal at birth, and then develop signs of dislocation or dysplasia during the ensuing months, with the hip seemingly slipping out of joint. This stresses the need for maintaining a high level of suspicion, and of seizing every opportunity to examine the hips of infants and young children. There is also an important medicolegal aspect, as many parents have been led to believe that all hip dislocation is recognizable at birth.

\section{Present Investigation}

Seven children (five girls and two boys) whose hips were examined at birth presented at Queen Mary's Hospital for Children with dysplasia or frank dislocation within the first two years of life. Clinical details are given in Table I. In no case was there any family history of hip disorder. Their ages at presentation were between 2 and 23 months, and in five there

Queen Mary's Hospital for Children, Carshalton, Surrey

GEOFFREY WALKER, F.R.c.S., Consultant Orthopaedic Surgeon was a moderate degree of ligamentous laxity. There were four normal pregnancies and deliveries, one forceps delivery (vertex), one presented as a breech but was successfully turned and delivered normally, and one was delivered as a breech with extended legs. No hip abnormality was detected shortly after birth in six of the babies, and the examiners included a professor of paediatrics, paediatric and obstetric junior staff, general practitioners, and midwives (Table II). In the remaining child a hip click was detected by an orthopaedic surgeon, but the joints were considered to be stable and clinically normal at that time.

A possible hip problem was suspected by the parents in the three eldest children (aged 7, 17, and 23 months), while hip disorders were detected in the four younger (aged 2, 3, 3, and 6 months) at routine medical examinations (Table III). Symptoms included a suspicion of leg length inequality in two children, and a foot which everted in one child.

Limitation of abduction in flexion, which is often absent at birth in complete dislocation, was the main clinical finding in six of the children. This useful but not invariable sign was absent in the oldest child in this series (aged 23 months), whose hips at that time I passed clinically as normal, but in whom an $x$-ray film revealed a dislocation (see Figure).

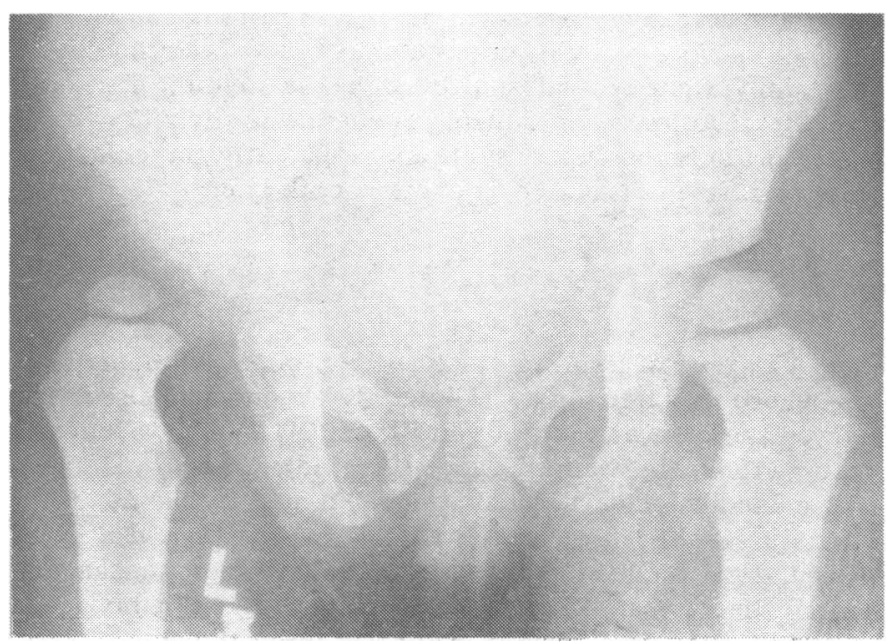

$X$-ray film of the hips of a girl aged 23 months with a left dislocation. This child presented with possible inequality of leg lengths. The hips at birth had been found to be clinically normal, and there was no limitation of abduction in flexion when examined by me at 23 months. 